\title{
A Interiorização dos Refugiados Venezuelanos no Brasil1
}

\author{
Luíza de Macedo Soares Vieira Carneiro²
}

\section{Resumo}

O artigo busca analisar a política de interiorização do governo brasileiro, praticada com o apoio de organizações internacionais, com o intuito de lidar com a chegada dos refugiados venezuelanos no estado de Roraima. Essa alternativa já havia sido escolhida em outra situação de estada prostrada em 2014, a fim de deslocar os refugiados haitianos. É necessário, portanto, compreender inicialmente o processo do aumento do fluxo de haitianos no Brasil; como está sendo realizado o processo de interiorização e entender o nexo militar-humanitário da política. Assim, buscar as dinâmicas tanto legais como práticas torna-se essencial à parte crítica da pesquisa, que pretende propor um meio de lidar com as situações de estada prostrada no Brasil.

Palavras-chave: Refúgio, Brasil, Venezuela, Interiorização, Operação Acolhida.

\section{Abstract}

This article seeks to analyze the interiorization policy of Brazilian Government, practiced with the support of international organizations, in order to deal with the arrival of Venezuelan refugees in the state of Roraima. Such alternative had already been chosen in another situation of prostrate stay in 2014 to displace Haitian refugees. It is necessary to understand initially the process of increasing the flow of Venezuelans in Brazil; how the interiorization process is being carried out and understand de militaryhumanitarian nexus on this policy. Thus, searching for both legal and practical dynamics becomes essential to the the critical part of this article, which intends to propose means to deal with situations of prostrate stay in Brazil.

Keywords: Refugee, Brazil, Venezuela, Interiorization, Shelter Operation

\section{Introdução}

Após a morte de Hugo Chávez, em março de 2013, a crise econômica na Venezuela se intensificou. Seu sucessor político, Nicolás Maduro, assumiu o governo no mês seguinte, para um mandato de seis anos. Decorridos 18 anos de governo chavista, em 2015, a oposição conquistou maioria no Parlamento, o que gerou um conflito entre os poderes. Nesse cenário, o Tribunal Superior de Justiça, aliado a Maduro, restringiu as funções legislativas da Assembleia Nacional. Logo, em abril de 2016, diversos protestos ocorreram nas ruas de Caracas, exigindo a saída de Maduro. Após quatro meses de confrontos, 125 pessoas morreram e uma crise de proporções humanitárias se estabeleceu no país (Brasil, 2018).

\footnotetext{
${ }^{1}$ Este artigo é resultado do Programa de Educação Tutorial do Instituto de Relações Internacionais da Pontifícia Universidade Católica do Rio de Janeiro (PET-TEPP/PUC-Rio).

${ }^{2}$ Graduanda em Relações Internacionais pelo Instituto de Relações Internacionais da Pontifícia Universidade Católica do Rio de Janeiro (IRI-PUC-RIO). E-mail: luiza-98@hotmail.com
} 
Uma das consequências da crise política e econômica na Venezuela é o deslocamento em larga escala de sua população para outros países, sendo o Brasil um dos destinos escolhidos. Desse modo, a fronteira norte brasileira entre a cidade brasileira de Pacaraima e a venezuelana de Santa Elena e Uairén, sem obstáculos naturais, transformou o Estado de Roraima no destino mais acessível no país (Marques \& Leal, 2018, p. 2). Nesse contexto, os migrantes venezuelanos têm enfrentado dificuldades de acesso aos serviços básicos na cidade de Boa Vista, assim como, a violência advinda da sociedade brasileira, sendo a xenofobia a principal forma de hostilidade sofrida. O governo brasileiro deve, portanto, adotar estruturas mais adequadas para a recepção, com o intuito de garantir o fim da ideia de que há uma competição pelo atendimento dos serviços estatais.

Assim, a cooperação entre as esferas do governo, a sociedade civil e os órgãos da Organização das Nações Unidas (ONU), torna-se a forma mais eficaz para preparar e implementar políticas públicas que capacitem e melhorem os serviços prestados. Além disso, precisa-se garantir a proteção dos direitos humanos e sociais dos venezuelanos a fim de superar desafios e dificuldades existentes na concepção e na implementação de uma agenda comum em favor do desenvolvimento mais igualitário.

Esse Plano de Ação regional estabelece o apoio técnico e logístico à estratégia de interiorização, que consiste em ajudar os venezuelanos em situação de vulnerabilidade a encontrar melhores condições de vida em outros estados, sem sobrecarregar nenhuma região, como o ocorrido em Roraima. Tal política foi adotada pelo Governo brasileiro respeitando, tecnicamente, a vontade do indivíduo migrante em participar desse processo, com a adesão voluntária, tendo o conhecimento sobre as condições que serão enfrentadas nas novas cidades de destino em termos de estrutura e assistência, como, emprego, moradia e serviços de saúde.

A presente pesquisa tem por objetivo realizar análises logísticas e de subjetividades da política de interiorização do governo brasileiro, praticada com o apoio de organizações internacionais, com o intuito de lidar com as situações de estada prostrada no Brasil. Esses conceitos de Garelli \& Tazzioli, vão ser mobilizados com o nexo militar humanitário característico da operação. Dessa forma, o estudo apresenta o processo do aumento do fluxo de venezuelanos no Brasil; como está sendo realizado o processo de interiorização; como é realizado o programa de reassentamento brasileiro; como o âmbito militar e humanitário interagem e quais são os desafios e as críticas de tal política. Assim, buscar as dinâmicas tanto legais como práticas torna-se essencial à parte crítica da pesquisa, que pretende propor qual é o melhor meio de lidar com as situações de estada prostrada no Brasil. 


\section{A questão venezuelana e o processo de interiorização}

A crise na Venezuela aumentou o fluxo de refugiados no Brasil, principalmente a partir do ano de 2015. A Organização Internacional para as Migrações (OIM) estima que 2,3 milhões de venezuelanos já deixaram o país. Estima-se, também, que pelo menos 50 mil, ou 2\% daquele total, tenham se fixado apenas no Brasil, até o mês de abril de 2018, o que representa um aumento de mais de $1.000 \%$ em relação ao ano de 2015 , considerando os pedidos de asilo e de residência (ONUBR, 2018, p. 18). Boa parte desses refugiados chega na cidade de Boa Vista, a maior cidade do estado menos populoso do Brasil, Roraima, com 500 mil habitantes, localizada a 210 quilômetros de distância da Venezuela (Batista et al., 2018, p. 5).

Devido ao transporte precário, muitos venezuelanos fazem o percurso a pé e, apesar das dificuldades encontradas, já representam mais de $10 \%$ da população de Roraima, uma vez que diariamente entram no Brasil entre 700 e 1.200 venezuelanos. Com isso, a economia local não tem capacidade de absorvê-los e a metrópole regional, Manaus, é ainda mais distante, já que dista 780 quilômetros (Batista et al., 2018, p. 5), o que faz com que a melhor oferta de serviços, direitos e trabalho esteja distante dos locais utilizados como entrada no país.

Desse modo, a acolhida dos venezuelanos torna-se mais problemática no Brasil do que na Colômbia e no Equador, dois outros países hospedeiros vizinhos (Batista et al., 2018, p. 5). A Colômbia, em sua grande parte, é uma área de trânsito para um terceiro país, cuja cidade de Bogotá, com aproximadamente 8 milhões de habitantes, é a que mais tem venezuelanos com a permissão de permanência especial (OIM, 2018a, p. 9). Do mesmo modo, o Equador reportou a maior entrada de venezuelanos na cidade de Rumichaca, na fronteira com a Colômbia, e o maior número de saídas na cidade de Huaquillas, fronteira com o Peru (OIM, 2018a, p. 2). Os venezuelanos são vítimas em seu país de origem e ao chegarem tornam-se, novamente, vítimas no território brasileiro, tendo em vista que as possibilidades de acesso ao Estado são limitadas, o que facilita seu processo de marginalização (Jarochinsky \& Jubilut, 2015, p. 346).

Essa dificuldade não atinge apenas a população migrante, mas os habitantes locais, que já recebem um atendimento bastante precário e que piora com a chegada dos estrangeiros, enxergados como aproveitadores dos serviços na região (Jarochinsky \& Jubilut, 2015, p. 339). Torna-se fundamental que os municípios adotem estruturas mais adequadas para a recepção, com o intuito de garantir o fim da ideia de que há uma competição pelo atendimento dos serviços estatais. Para isso, há que se preparar e implementar políticas públicas que capacitem e melhorem os serviços prestados (Jarochinsky \& Jubilut, 2015, p. 342). 
Somado a isso, apelos para o fechamento da fronteira foram encaminhados do governo de Roraima ao Supremo Tribunal Federal (STF), mas um parecer da Advocacia-Geral da União afirma que tal medida violaria tratados internacionais (Batista et al., 2018, p. 6; STF, 2018a). A Ação 3121 pedia o imediato fechamento temporário da fronteira Brasil-Venezuela, com pedido de tutela provisória de urgência à União, impedindo a entrada de cidadãos venezuelanos no estado de Roraima. A tutela visou a tentativa de garantir a promoção de medidas de controle policial, saúde e vigilância sanitária. Além disso, a governadora Suely Campos pediu que a União efetuasse a imediata transferência de recursos adicionais, um total de $\mathrm{R} \$ 184$ milhões, para cobrir os custos do estado, especialmente nas áreas de saúde, segurança e educação dos venezuelanos (STF, 2018b). Entretanto, a Ministra Rosa Weber rejeitou o pedido.

Entretanto, o governo de Nicolás Maduro anunciou o fechamento da fronteira com o Brasil em fevereiro de 2019, após a tentativa de países vizinhos, incluído o Brasil de enviar ajuda humanitária ao país. Maduro entendeu o ato como uma interferência externa em sua política e o fechamento terrestre perdurou até maio do mesmo ano, quando o presidente declarou a reabertura em rede internacional, depois de inúmeras reuniões com as Forças Armadas do Brasil, a Força Armada Bolivariana, o governo de Roraima, a prefeitura de Pacaraima, senadores e os setores produtivos (G1, 2019).

Segundo a avaliação dos representantes do ACNUR no Brasil, o caso é típico de fluxo misto, ou seja, um fluxo que reúne pessoas que se enquadram nas hipóteses específicas para a concessão do refúgio e outras em condição migratória distinta, como o dos venezuelanos (p. 17). Esses fluxos são definidos pela a Organização Internacional de Migração (OIM) como:

[...] movimentos de população complexos, que incluem refugiados, solicitantes de asilo, migrantes econômicos e outros migrantes. Além disso, ela ainda salienta que esse tipo de fluxo está relacionado com movimentos irregulares, nos quais há, com frequência, migração de trânsito, com pessoas que realizam o movimento sem a documentação necessária, atravessam fronteiras e chegam ao seu destino sem autorização (OIM, 2018c, p. 1).

Tendo em vista o interesse pela cidade de Pacaraima, devido à grande chegada de migrantes, foi estabelecido o Decreto n. ${ }^{\circ} 36$, que declara situação de emergência e desenvolve ações humanitárias no município.

As autoridades brasileiras pretendem, por meio de um discurso de descrever o movimento migratório como uma "invasão" ou um "êxodo", obter cada vez mais recursos da União ou a fim de justificar os serviços insuficientes dos órgãos estatais (Jarochinski, 2017, p. 9-10). Assim, o cenário atual mostra que os solicitantes não serão reconhecidos como 
refugiados, mas sendo enquadrados como sujeitos a uma Grave e Generalizada Violação de Direitos Humanos (GGVDH), o que poderia desencadear um reconhecimento, tendo em vista a não obtenção de itens básicos, como alimentos e medicamentos. Logo, a possibilidade de reconhecimento, apesar de prevista na lei brasileira, não se configura como um direito, mas sim como uma decisão discricionária do governo (Jarochinski, 2017, p. 13).

Devido ao peso político advindo do status migratório, questionamentos surgiram acerca de sua categorização em relação aos venezuelanos, muito em função ao tratamento dado a eles a partir de sua definição (Neai, 2018). O coordenador-geral do CONARE (Comitê Nacional para os Refugiados), Bernardo Laferté, afirma que o órgão ainda analisa qual será o status adequado para, em seguida, definir questões como, por exemplo, as restrições sobre um retorno à Venezuela $(B B C, 2018)$. Do mesmo modo se posiciona o ACNUR, pois considera Grave e Generalizada Violação dos Direitos Humanos, mas não aponta qual deve ser o status migratório dos venezuelanos. O Núcleo de Estudos e Análises Internacionais (NEAI) da Universidade Estadual Paulista (UNESP) afirma que de fato existem elementos na crise venezuelana que podem ser compreendidos como GGVDH, só que não é possível descartar as perseguições políticas no atual cenário do país (NEAI, 2018).

O Conselho Nacional de Direitos Humanos (CNDH) realizou recomendações no dia 23 de outubro de 2018 sobre a situação dos migrantes venezuelanos no Brasil. Deseja que o Estado brasileiro considere "objetivamente a existência de grave e generalizada violação de direitos humanos na Venezuela", assim possibilitando o reconhecimento como refugiados dos migrantes acolhidos no país. Além disso, cobra o cumprimento de funções do CONARE, como visitas nas regiões com maior concentração dos solicitantes de refúgio, a fim de coordenar as ações de proteção aos refugiados. No mesmo dia, foi aprovada uma resolução da ONU acerca do reconhecimento da grave crise política, econômica, social e humanitária da Venezuela, com o pedido de que o país aceite ajuda de remédios e alimentos (Conectas, 2018). No entanto, o reconhecimento de algum venezuelano como refugiado no Brasil ainda não ocorreu, tendo em vista a falta de consenso sobre a motivação de tais fluxos. Dessa forma, as autoridades brasileiras concedem um visto de residência temporária de dois anos para os venezuelanos que chegassem por terra.

Torna-se evidente que a decisão de reconhecer o status de refugiado em virtude de uma Grave e Generalizada Violação de Direitos Humanos traz impactos diplomáticos significativos entre os países. A análise deixa de ser pautada em uma perspectiva individual do bem-fundado temor de perseguição para uma situação generalizada no local de origem do solicitante, no caso, 
a Venezuela. Ainda mais agravada pelo fato de serem nações fronteiriças, pertencentes a organizações regionais comuns (Jarochinski, 2017, p. 13).

Por isso, com base nos motivos elencados na EMI n 1 /2018 CC-PR/MJSP/MD/GSIPR de 15 de fevereiro de 2018, os senhores Eliseu Padilha, Torquato Jardim, Raul Jungman, Sergio Westphalen Etchegoyen encaminharam ao Presidente Michel Temer a urgência da edição da Medida Provisória, necessária para controlar e ordenar o fluxo migratório advindo da República Bolivariana da Venezuela (Planalto, 2018). Tal medida foi promulgada no dia 15 de fevereiro de 2018, sob $\mathrm{n}^{\circ}$ 820, que dispõe sobre medidas de assistência emergencial para acolhimento de pessoas em situação de vulnerabilidade decorrente de fluxo migratório provocado por crise humanitária e cria Comitê Federal de Assistência Emergencial, que será regulamentado posteriormente (Casa Civil, 2018).

Dois decretos foram promulgados, no mesmo período, o Decreto n. ${ }^{\circ}$ 9.285/2018 e o Decreto n. ${ }^{\circ}$ 9.286/2018. O primeiro reconheceu a situação de vulnerabilidade e o aumento populacional temporário, desordenado e imprevisível observado no Estado de Roraima em decorrência do fluxo migratório de pessoas advindas da República Bolivariana da Venezuela. O segundo definiu a composição, as competências e as normas de funcionamento que o Comitê Federal de Assistência Emergencial deliberará por meio de resoluções (Câmara dos Deputados, 2018).

Em 21 de junho de 2018, foi finalmente promulgada a Lei $\mathrm{n}^{\circ} 13.684$, que dispõe sobre as medidas de assistência emergencial para o acolhimento das pessoas em situação de vulnerabilidade, bem como cria as Comissões Intergestores Tripartite, a fim de coordenar as questões operacionais dos serviços de saúde, e a Comissão intergovernamental de Financiamento para a Educação Básica de Qualidade, com o intuito de coordenar os recursos para aplicação na melhoria da qualidade da educação básica e cria as diretrizes do Comitê Federal e sua aplicação (Casa Civil, 2018).

Em função disso, o governo brasileiro optou por realizar o processo de interiorização. Esse processo é definido como o deslocamento de uma parcela da população às cidades menos populosas, especialmente as localizadas nas periferias das regiões metropolitanas (Cutti et al., 2018, p. 163). A decisão de realizar essa política com os refugiados venezuelanos leva em consideração os equívocos ocorridos na tentativa realizada em 2014 em relação aos haitianos. Isso porque, o governo do Acre alugou ônibus para os imigrantes, mas sem contar com o apoio da União, o que gerou tensões com os governos dos outros estados do país, pois a sociedade civil improvisou o acolhimento (Migramundo, 2018a). 
O governo do Rio Grande do Sul encaminhou ao governo do Acre um ofício em que manifestava inconformidade com suas ações. Isso porque, não foi estabelecida um procedimento formal de comunicação entre os estados, com o objetivo de permitir a previsibilidade e o planejamento para a recepção dos haitianos, que souberam do transporte por meio de notícias da mídia, acusação negada pelo governo do Acre. Assim, foi solicitado o encaminhamento deles para outros estados, como São Paulo, Paraná e Santa Catarina, pois eles também não manifestavam o desejo de permanecer no local(G1, 2014).Desse modo, a atual interiorização busca realizar o transporte em conjunto com as Forças Armadas, sem a imediata contratação de uma empresa privada, com aviso prévio aos estados, que estabelecem sua disponibilidade de recepção e a assinatura do refugiado de um termo de voluntariedade ${ }^{3}$ para que não sejam deslocados sem a vontade de permanecer no local.

A ACNUR e a OIM, com a ajuda de outras agências das Nações Unidas, permanecem trabalhando com o governo brasileiro, que instituiu o Subcomitê Federal de Interiorização dos Imigrantes para realizar a transferência de venezuelanos da região Norte para outras cidades do país. Dessa forma, a promessa do processo de interiorização era de que tornaria as perspectivas de integração e realizaria soluções de longo prazo para as pessoas venezuelanas, além de possibilitar a redução da pressão no Estado de Roraima por meio da abertura de vagas nos abrigos temporários existentes em outros Estados. Estimava-se que outros 800 venezuelanos seriam interiorizados até o final de setembro de 2018, mas em julho de 2018, 820 pessoas já haviam sido interiorizadas, de acordo com a OIM (2018c).

É preciso ter em mente que se deve respeitar os princípios de livre movimento no território nacional de migrantes e refugiados, tendo em vista que estes estão em condição de igualdade com os nacionais, de acordo com o Art. $4^{\circ}$, inciso II da Lei de Migração n. ${ }^{\circ}$ 13.445/2017, de 24 de maio de 2017 (Brasil, 2017). Tal artigo garante o direito à liberdade de circulação em território nacional, em que o indivíduo deve ter a vontade de adesão voluntária, embasada em uma tomada de decisão informada. Isto é, ter conhecimento sobre as condições que serão enfrentadas nas novas cidades de destino em termos de estrutura e assistência, como, emprego, moradia e serviços de saúde.

A Secretaria Nacional de Cidadania do Ministério dos Direitos Humanos solicitou a OIM Brasil, que atua sobre o fluxo migratório venezuelano no estado de Roraima desde agosto de 2017, em conjunto ao Governo do Brasil, a aplicação da Matriz de Monitoramento de Deslocamento. Esta é uma ferramenta global da OIM, que coleta, processa e difunde

\footnotetext{
${ }^{3}$ Anexo A - Formulário de Declaração de Voluntariedade.
} 
informação sobre mobilidade humana, ao perfil dos migrantes e suas necessidades (OIM, 2018 c, p. 1). Sua pesquisa revelou que $65 \%$ dos refugiados estão interessados no processo de interiorização, 32\% não estão interessados e 3\% não deram respostas (OIM, 2018c, p. 5).

Com o intuito de viabilizar o acolhimento dos indivíduos, em primeiro lugar, o ACNUR estabelece o perfil da população e identifica os interessados em participar da estratégia. A OIM e o Programa Voluntário de Apoio ao Retorno e Reintegração são responsáveis pela organização de reuniões que explicam e encorajam o programa de vagas em abrigos das prefeituras, nos governos estaduais e na sociedade civil (Tuzun, 2018, p. 1704). Segundo a Casa Civil, a política de interiorização se inicia na etapa preparatória com a articulação política. Nessa etapa é necessário o diálogo do governo brasileiro com os possíveis estados e cidades de destino, de acordo com a disponibilidade de vagas em abrigos de prefeituras, governos estaduais e na sociedade civil para receber os imigrantes, uma vez que o deslocamento só será feiro mediante a concordância em recebê-los. Além disso, é preciso contatar as entidades da sociedade civil e empresariais, a fim de identificar seus interesses em receber os refugiados e identificar as redes de serviços públicos ou privados disponíveis (Tuzun, 2018, p. 8).

Após a identificação de todos os fatores é iniciada a preparação do imigrante por meio de seu cadastramento. Assim, o indivíduo deve ter sua situação de documentação migratória regularizada para receber as orientações sobre gênero, proteção e a declaração de voluntariedade e será feita uma avaliação clínica, com sua imunização adequada de acordo com o Ministério da Saúde (Casa Civil, 2018, p. 8). O ACNUR garante que os venezuelanos que se voluntariam para este processo tenham os documentos apropriados para viajar, como $\mathrm{CPF}$, carteira de trabalho e de vacinação (ONUBR, 2018), com prioridade para os migrantes residentes em abrigos públicos de Roraima (Casa Civil, 2018, p. 1). As Forças Armadas Brasileiras estão encarregadas da fase de deslocamento que pode ser feito por meio de voos comerciais ou por via terrestre, dependendo do tamanho do grupo ou do tipo de abrigo e moradia que o refugiado ficará. O Governo Federal, a OIM, o ACNUR e a UNFPA organizam e articulam a recepção dos deslocados desde sua chegada ao aeroporto ou base aérea até as cidades de destino, abrigo ou residência (OIM, 2018b, p. 8).

Existem diversas modalidades de abrigos de interiorização, realizadas por meio da identificação e a seleção dos possíveis beneficiários. Nas moradias providas por organizações, esse processo é realizado pelas mesmas, que os encaminhará ao cadastramento realizado pelo ACNUR. O contato com a entidade da sociedade civil na cidade de recepção é realizado pelo 
ACNUR e o Ministério de Desenvolvimento Social a fim de confirmar a disponibilidade para receber os refugiados situados no estado de Roraima (Casa Civil, 2018, p. 9).

Já para interiorização vinculada ao trabalho, a empresa interessada na contratação de imigrantes deve buscar a Superintendência Regional do Trabalho (SINE) de sua cidade para realizar o cadastramento das vagas de trabalho no portal Emprega Brasil, assim como os nacionais, definindo o perfil e a formação do venezuelano. Com essas informações, é feita a convocação entre os refugiados cadastrados no portal e situados em Roraima, com o apoio de organizações da sociedade civil que já têm feito o trabalho de intermediação. Após a seleção, o refugiado deverá assinar o contrato de trabalho ainda em Roraima para depois ser transportado e receber moradia temporária inicial custeada pela empresa ou em abrigos públicos ou da sociedade civil (Casa Civil, 2018, p. 10).

A reunificação familiar depende da identificação dos possíveis beneficiários e é realizada pelo ACNUR ou pela sociedade civil entre os residentes em Roraima. O contato com a família que reside em outra cidade é realizado pela OIM com o intuito de confirmar contatos, vínculos e a real disponibilidade de recepção. Além disso, a Cruz Vermelha do Brasil pode ser usada como apoio para a localização dos familiares (OIM, 2018d, p. 10). A modalidade de abrigo para mulheres e público LGBT os beneficia em situação de vulnerabilidade e risco, como violência sexual, doméstica, intrafamiliar, submetidos a tráfico humano e ameaças de morte, identificados nos abrigos em Roraima ou identificados nos postos de triagem. A gestão desses casos é feita pelas instituições das casas de abrigo, pela ACNUR, pela UNFPA e pelos Ministérios responsáveis, como o de Direitos Humanos e o de Desenvolvimento Social (OIM, 2018d, p. 11).

Ainda assim, há uma lacuna na participação da sociedade civil e do setor empresarial, fundamentais para a integração e ao crescimento dos refugiados, como sua inserção no mercado de trabalho (Jarochinski \& Jubilut, 2018a). O Subcomitê de Interiorização realizou oito seminários para a tentativa de uma melhor inserção socioeconômica dos migrantes venezuelanos. Tais seminários têm como intuito a sensibilização do empresariado brasileiro para a contratação dos venezuelanos. Nesse espaço, os empresários podem tirar dúvidas acerca da nova Lei de Migração e da legislação trabalhista e compartilhar casos de sucesso de imigrantes empregados em suas empresas (Casa Civil, 2018, p. 4).

Os seminários Nova Lei de Migração - Uma Janela de Oportunidades já foram realizados em Boa Vista, São José, São Paulo, Curitiba, Porto Alegre, Manaus, Sorocaba e Campinas (CASA CIVIL, 2018, p. 4). Em Porto Alegre, por exemplo, o seminário contou com 
a participação do Instituto Lojas Renner para relatar os casos de sucesso na contratação de imigrantes (BRDE, 2018). Já em Campinas, os casos de sucesso relatados contaram com a gerente de Responsabilidade Social e Diversidade do Carrefour Brasil, Karina Chaves, com o Diretor da área de recursos humanos da $P \& G$ e com a responsável pela área de Diversidade \& Inclusão da Sodexo do Brasil, Lilian Rauld (FIESP, 2018). A Sodexo contratou, em todo o Brasil, aproximadamente 70 funcionários migrantes e/ou refugiados (ACNUR, 2018).

Desse modo, a interiorização consiste em ajudar os venezuelanos em situação de vulnerabilidade a encontrar melhores condições de vida em outros estados, sem sobrecarregar nenhuma região (Tuzun, 2018, p. 1704) e, por isso, não terá custos financeiros para os venezuelanos. As viagens são custeadas com R\$ 190 milhões garantidos pela União ao Ministério da Defesa, por meio da Medida Provisória $n^{\circ}$ 823/2018 para a assistência emergencial. Além disso, todos os deslocados devem ser imunizados, com os prazos de carência das vacinas já cumpridos, em relação às doenças como sarampo, caxumba, rubéola, febre amarela, difteria, tétano e coqueluche (Ministério da Defesa, 2018). Foi criado um Centro de Trânsito em Pacaraima para uma colaboração entre o Governo Federal, a OIM e o ACNUR. O Centro fornece assistência de documentação e informações sobre alternativas de realocação voluntária (OIM, 2018a, p. 4).

Por meio do grau de escolaridade, profissão, idade, gênero, situação familiar e estado civil, os refugiados são organizados em abrigos espalhados pelo país com os mesmos critérios e, assim, têm a possibilidade de tentar reconstruir suas vidas em outros locais (Tuzun, 2018, p.1708). As cidades hospedeiras também recebem esses refugiados de forma voluntária, como, por exemplo, São Paulo (Migramundo, 2018b). Alguns exemplos disso são os abrigos CTA (Centros Temporários de Acolhimento). Na cidade de São Mateus, em São Paulo, a organização aceitou apenas homens. Os abrigos no Rio de Janeiro aceitaram famílias e o abrigo Don Jackson, em Manaus, apenas mulheres solteiras ou solteiras com filhos (Tuzun, 2018, p. 1708).

Todas essas questões são estruturadas por meio da Operação Acolhida, coordenada pelo governo federal, com apoio técnico do ACNUR e da OIM instaurada pela Força Tarefa Humanitária, subdivididas em fases e equipes distintas. Algumas delas são a Implementação de Abrigos; Assistência; Gestão de Abrigos, Estratégia de Interiorização, Operação Gestão de Fronteira que reestruturou a fronteira de Pacaraima (OIM, 2018d). Nesta última, foi realizada a ampliação e requalificação das estruturas físicas do Posto de Identificação e Recepção, Posto de Triagem e Posto de Saúde (OIM, 2018d), com o intuito de aprimorar as bases voltadas à segurança. 
De acordo com a Força Tarefa Humanitária de Roraima, 5.256 venezuelanos já foram realocados para São Paulo (951), Rio Grande do Sul (893), Amazonas (523), Santa Catarina (482), Paraná (400), Distrito Federal (292), Rio de Janeiro (277), Pernambuco (265), Mato Grosso do Sul (252), Paraíba (243), Mato Grosso (192), Bahia (125), Rondônia (123), Rio Grande do Norte (91), Minas Gerais (76), Sergipe (35), Goiás (20), Roraima (15), Espírito Santo (1) (2019).

\section{Nexo militar-humanitário}

Com o intuito de realizar uma análise acerca da interiorização, é possível focar no nexo militar-humanitário, a fim de estudar seu desenvolvimento e mapear seus resultados para a mobilidade dos migrantes e para os atores envolvidos. Nesse sentido, o artigo utiliza abordagens de análise teóricas sobre cooperação civil-militar e sobre a tecnologia militar-humanitária. As relações entre civis e militares foram inicialmente formadas a fim de preencher as lacunas das capacidades civis em campo, por meio das capacidades tradicionais militares.

No entanto, em resposta à crescente complexidade dos requisitos operacionais, principalmente depois da Segunda Guerra Mundial, os Estados intensificaram a cooperação entre civis e militares (CIMIC), desenvolvendo as suas próprias doutrinas (Franke, 2006, p. 78). A ONU compreende a CIMIC como "uma função de equipe militar que contribui para facilitar a interface entre os componentes militar e civil de uma área de missão integrada" (2010, p. 2, tradução nossa). ${ }^{4}$ Desse modo, a cooperação civil-militar inclui três funções principais: a ligação entre os militares e todos os atores civis na área de operação; a assistência ao ambiente civil e o apoio à força (Franke, 2006, p. 8).

A cooperação entre ambos tem como principal característica ser interdependente. Isso porque, os civis precisam do fornecimento de informações sobre o terreno e a população e, em condições de ameaça, geralmente dependem de transporte e logística fornecidas pelos militares. Do mesmo modo, as forças armadas precisam dos civis, que por sua vez, promovem a assistência humanitária e possuem conhecimento e experiência na construção, reconstrução e desenvolvimento em áreas devastadas, papel muitas vezes realizado por ONGs (Roberts, 2010, p. 213). Nesse sentido, ambas operam em prol da segurança humana, alinhando a perspectiva militar, de segurança, com a civil, fornecendo necessidades básicas.

\footnotetext{
${ }^{4}$ No original: "a military staff function that contributes to facilitating the interface between the military and civilian componentes of an integrated mission area" (Franke, 2010, p.7-8).
} 
Além disso, as forças armadas geralmente possuem uma abundância de recursos, o que pode auxiliar em momentos de menor oferta, quando ocorre um desastre ou é necessário ter uma resposta rápida por exemplo (Weiss, 2005, p. 9). A adequação do uso de recursos é utilizada para sustentar valores humanitários, ou seja, determinar quando e onde são úteis ou não é a mesma capacidade relevante para crises domésticas, podem ser aplicadas no âmbito internacional. Assim, as autoridades políticas convocam as forças armadas para um país mais pobre em recursos, a fim de auxiliar em um desastre, como um complemento a atuação civil, o que é feito também nas operações de paz da ONU (Weiss, 2005, p. 10). Todavia, muitas vezes se mostra conflitante com uma abordagem do fenômeno migratório pautado nos Direitos Humanos, pois o viés securitário estabelece a visão de que o elemento externo ou estrangeiro representa uma ameaça, dificultando a implementação de políticas pautadas na recepção das pessoas (Jarochinsky \& Jubilut, 2015, p. 343).

As organizações humanitárias mostram preocupações sobre o impacto da cooperação civil-militar em permanecerem imparciais e independentes (Franke, 2006, p. 6). Com o intuito de compreender os desafios, as escolhas e as oportunidades da relação entre civis e militares, os profissionais e pesquisadores analisam a os mecanismos apontados por Galbraith em sua abordagem intraorganizacional de processamento de informações. Ele identifica cinco estratégias de coordenação diferentes: as regras e programas; hierarquia; objetivos e metas; redução da necessidade de processar informações e aumento da capacidade de processar informações lateralmente, a fim de superar os desafios que surgem (Roberts, 2010, p. 217-218).

Procedimentos operacionais padrões são tentativas de estabelecer regras para governar o espaço humanitário, mas com o fim da Guerra Fria, essas regras pré-estabelecidas foram desafiadas, pressionando as relações civis militares, logo, recorreriam à hierarquia. Por isso é importante definir previamente quem controla a operação, que no caso da Operação Acolhida, é o exército brasileiro que orienta as metas e os esforços necessários. Já na redução da necessidade de processar informações, as organizações tanto militares quanto civis podem diminuir o número de atividades a serem realizadas, reduzindo os níveis de amplitude, desacoplando suas atividades de outras organizações para operarem como entidades autônomas. Por fim, os contatos diretos entre ambas, por meio de mecanismos laterais formais para direcionar as ações no teatro de operações, que normalmente são predominantes (Roberts, 2010, p. 2018). Dessa forma é possível superar os desafios e construir uma boa cooperação civilmilitar. 
No texto The Humanitarian War Against Migrant Smugglers at Sea, de Garelli \& Tazzioli abordam como tecnologia militar-humanitária envolvida na gestão da migração no Mediterrâneo é utilizada em uma operação da União Europeia para conter o tráfico. Elas apresentam abordagens multifocais de análise, a de logística; de subjetividade e de epistemologia. A logística do movimento migratório, foca na infraestrutura das viagens dos migrantes, comparando duas operações. Posteriormente, focam na logística do humanitarismo militar, ou seja, sua implementação, protocolos e resultados. Além disso, é feito um diagnóstico da subjetividade, procurando os perfis dos migrantes em que esta operação funciona; e epistemologia, com base no primeiro estágio de inteligência, na coleta de dados da missão e nas conversas da comunidade epistemológica. Assim, focam na abordagem militar-humanitária para estudar a produtividade do governo da mobilidade (Garelli \& Tazzioli, 2018b, p. 685).

Os refugiados se tornam alvos da intervenção militar-humanitária, o que permite observar um princípio base do humanismo, ou seja, a proteção da vida (Garelli \& Tazzioli, 2018b, p. 689). Dessa forma, o objetivo não é realizar uma análise do humanitarismo e nem do militarismo, mas do gerenciamento da produção. No caso da interiorização venezuelana, as Forças Armadas e as agências humanitárias trabalham em conjunto, com a finalidade de proteger os refugiados e, mais especificamente, a população de Roraima. As Forças Armadas reúnem seus esforços para dar um apoio operacional e logístico, enquanto as agências humanitárias garantem o apoio técnico. O nexo militar-humanitário desconstrói a dicotomia geralmente presente entre os dois conceitos, em que suas agendas têm finalidades iguais, uma vez que carregam um princípio base comum, ou seja, a proteção da vida (Garelli \& Tazzioli, 2018b, p. 686).

No caso brasileiro, as Forças Armadas e a Polícia Federal são os órgãos estatais que se estabelecem também nas fronteiras do país, a fim de realizar sua função frente à segurança do Estado. Entretanto, muitas vezes sua abordagem se mostra conflitante com uma política migratória pautada nos Direitos Humanos. Tal viés securitário estabelece uma lente em que o elemento externo, ou seja, o estrangeiro, representaria uma ameaça ao Brasil, o que dificulta a implementação de políticas baseadas na recepção das pessoas (Jarochinsky \& Jubilut, 2015, p. 343).

Apesar disso, o Exército brasileiro possui experiência na realização de Ações CívicoSociais (ACISO) em toda a região amazônica. Assim como os conhecimentos adquiridos no exercício multinacional denominado Amazonlog, realizado em 2017, têm contribuído significativamente no apoio aos migrantes venezuelanos. Durante o Amazonlog, os militares 
planejaram e praticaram atividades como o controle de zoonoses, programas de segurança alimentar, montagem e operação do Hospital de Campanha (H Camp) e testes de equipamentos (Franchi, 2019, p. 10).

Em paralelo, os abrigos federais são arranjos pactuados em reuniões com os governos locais e entidades da sociedade civil, a depender das oportunidades e restrições de cada localidade. Essas possibilidades viriam desde o modelo de operação logística do Amazonlog, em que a infraestrutura é mantida pelo Ministério da Defesa, com gestão do ACNUR e seus parceiros, até uma estrutura de responsabilidades conjugadas e compartilhadas entre o governo federal, estadual, municipal, sociedade civil e organizações internacionais (OIM, 2018d, p. 11). O modelo do H Camp, por exemplo, foi praticado em Pacaraima, com o intuito de auxiliar no atendimento básico de saúde aos venezuelanos, desde abril de 2018 (Franchi, 2019, p. 10).

Sendo assim, deve-se observar que as forças militares, sem o comando das Nações Unidas, são utilizadas para garantir o suporte humanitário aos deslocamentos forçados desde a Segunda Guerra Mundial. Porém, especialistas da área de Defesa afirmam que esse não é o cenário ideal, pois essa não é sua função essencial, que seriam ligadas ao preparo para o emprego em conflitos armados. Entretanto, a participação das Forças Armadas brasileiras não se enquadra em uma lente de securitização ou militarização do deslocamento, mas que auxilia em uma maior agilidade frente aos desafios humanitários (Franchi, 2019, p. 11).

A partir dessas ideias, o presente artigo utiliza as abordagens logísticas e de subjetividade, com o intuito de analisar a política de interiorização. Por meio da análise logística, busca-se avaliar a infraestrutura, a escolha de quem será interiorizado, a documentação necessária, os meios de transporte, a chegada nos novos estados e a integração. O objetivo do processo de interiorização é de possibilitar a redução da pressão em Roraima por meio da abertura de vagas nos abrigos temporários existentes em outros estados, oferecendo novas oportunidades de integração. Os migrantes são transportados após seu cadastramento por voos comerciais ou por via terrestre (OIM, 2018d, p.8).

Além disso, a sociedade civil também realizou algumas viagens do processo de interiorização, que contou com diversas entidades. Segundo o controle da Força Tarefa Logística Humanitária no Estado de Roraima 2.407 venezuelanos foram interiorizados por esse segmento. A Igreja de Jesus Cristo dos Santos dos Últimos Dias (Mórmons) foi responsável pela maior quantidade, 1499 pessoas; a Pastoral Universitária por 308; a Fraternidade sem Fronteira por 225; os Serviços Jesuítas por 216; a Cáritas por 94; a Associação dos Adventistas (ADRA) por 42 e os Jovens Com Uma Missão (JOCUM) por 18 (2019, p. 60). O trabalho dos 
mórmons em parceria com o governo federal teve início ainda no governo do Presidente Michel Temer. Em 2018, os voluntários da igreja conseguiram parcerias com três companhias aéreas, a Azul, a Gol e a Latam, com o intuito de conseguir cortesia nos voos para transportar os venezuelanos para diversos estados brasileiros, auxiliando assim, no processo de interiorização (Folha de São Paulo, 2019).

As Forças Armadas atuam na promoção de auxílio humanitário às comunidades ribeirinhas na Região da Amazônia e emergencialmente em catástrofes naturais de grande porte como as enchentes e deslizamentos (Gonçalves et al., 2014, p. 5). Em comparação ao caso dos haitianos em 2014, o primeiro passo da logística do deslocamento foi melhorado. Tendo em vista que o processo dos haitianos foi realizado sem um diálogo com a União, gerando tensões entre os governos estaduais (Migramundo, 2018c). A interiorização dos venezuelanos tem sido mais organizada. Isso pois há um maior diálogo entre as partes, já que as prefeituras, governos estaduais e a sociedade civil disponibilizam as vagas para receber os imigrantes, uma vez que o deslocamento será feito apenas mediante a concordância em receber. Sendo assim, o acolhimento não é mais feito de modo improvisado, como o visto em 2014.

No entanto, como a proteção é fornecida aos refugiados venezuelanos e que tipo de proteção é decretada por esse programa militar-humanitário? (Garelli \& Tazzioli, 2018b, p. 690). O deslocamento é fornecido não de modo individual e autônomo pelo refugiado, mas de forma orientada pelo governo brasileiro. Por meio do cadastramento feito para a participação da política de interiorização, o venezuelano é direcionado ao estado por meio de critérios, o seu grau de escolaridade, profissão, gênero, situação familiar e estado civil. Assim sendo, as Forças Armadas possuem os aparatos logísticos para lidar com a situação, uma vez que incluem os aparatos do Exército, Marinha e Força Aérea de modo conjunto.

Após a chegada aos estados determinados, o Governo Federal, a OIM, o ACNUR e a UNFPA organizam e articulam a recepção dos deslocados desde sua chegada ao aeroporto ou base aérea até as cidades de destino, abrigo ou residência (OIM, 2018d, p. 8). Isso aponta mais um ponto complementar no processo logístico de interiorização dos refugiados venezuelanos. Além disso, itens não alimentícios foram distribuídos para um total de 856 venezuelanos, que receberam produtos de higiene em Mucajaí, Canta e Alto Alegre (Roraima, Brasil), após a OIM realizar exercícios de avaliação de necessidades, concluídas em seis municípios, e finalizar os acordos de distribuição com a Caritas Brasil, as Forças Armadas e os governos municipais (OIM, 2018a, p.5). 
Todavia, ao olhar para as logísticas das viagens de interiorização, é possível observar outro efeito. Na medida em que os refugiados se tornam alvos de uma política militarhumanitária, é gerada uma gestão do fluxo migratório (Garelli \& Tazzioli, 2018b, p. 687) dentro do Brasil. Isso porque, ao invés de os venezuelanos irem para uma cidade qualquer, ou de seu desejo, eles são deslocados para um local determinado, que já estará pronto para recebê-los, a partir dos critérios estabelecidos pelos abrigos (Tuzun, 2018, p. 1708). Logo, direcionando onde os refugiados devem ir dentro do país.

Diante desse fator organizacional, a análise de subjetividade, que os molda e os postula como alvos do governo (Garelli \& Tazzioli, 2018b, p. 687) pode ser encontrada uma vez o movimento migratório é um movimento de fluxo misto. O termo subjetividades é apresentado no plural, tendo em vista a multiplicidade de perfis de migração que são produzidos e visados pela abordagem militar-humanitária à gestão dessa migração (Garelli \& Tazzioli, 2018b, p. 687). Os perfis desses migrantes podem ser diferentes, como solicitantes de asilo ou migrantes econômicos, fator diretamente relacionado com a característica de um movimento irregular, em que existem pessoas sem a documentação adequada que atravessam as fronteiras (OIM, 2018c, p.1) da Venezuela.

A análise destaca ainda outra camada de violência a qual os refugiados são alvos. A violência presente na fronteira que caracteriza a regulamentação da documentação e ao acesso à proteção internacional. Para que o refugiado participe do processo de interiorização, ele deve ter a documentação em dia, assim como o cartão de vacinação e o CPF, caso o contrário ele não poderá receber os benefícios do processo, podendo tentar sair do estado de Roraima por conta própria, estando exposto a riscos.

Dessa forma, os refugiados são tratados como sujeitos de risco, duplamente vitimizados, em que sua figura vulnerável é a marca do humanitarismo militar, descritos como "sujeitos de risco" e "sujeitos em risco". A subjetividade móvel é formulada, a fim de responder à necessidade de dar conta de uma dupla proteção, para lidar tanto com a insegurança dos refugiados, quanto a da população local, devido ao suposto aumento da violência em Roraima. Nesse contexto, o humanitarismo se torna a estrutura para o direcionamento dos refugiados em trânsito (Garelli \& Tazzioli, 2018b, p. 687), governando, desacelerando e desviando os movimentos autônomos dos migrantes em certos espaços, mantendo-os em movimento para manter um controle sobre a mobilidade para distinguir quem precisa de proteção internacional (Garelli \& Tazzioli, 2018a, p. 3). 
A partir dessa análise de subjetividades, pode-se mapear os espaços discursivos que o humanitarismo militar produz, a fim de estabelecer os seus objetivos de atuação. Logo, o uso dos perfis de migração tem como função reorganizar as viagens migratórias, mostrando os diferentes espaços de governamentabilidade que o processo de interiorização apresenta. Os espaços materiais de controle de migração, vistos na análise logística e os perfis migratórios presentes na abordagem de subjetividades são esses espaços de controle militar-humanitário (Garelli \& Tazzioli, 2018b, p. 698).

\section{Considerações finais}

Devido à necessidade de lidar com o aumento do fluxo de venezuelanos no Brasil, o governo brasileiro, com o apoio de organizações internacionais, desenvolveu o processo de interiorização. Esse processo busca diminuir a sobrecarga de recepção no estado de Roraima, principal porta de entrada no país, e visa gerar um melhor acesso aos serviços básicos, como o de saúde. Todavia, os dados sobre reintegração dos migrantes na sociedade e a diminuição das dificuldades de acolhimento no estado não se mostram suficientes para afirmar o sucesso de tal política para lidar com os processos de estada prostrada no país. Logo, deve-se trabalhar a longo prazo o acompanhamento dos participantes, a fim de, no futuro, ser realizado um diagnóstico mais profundo sobre o funcionamento da política.

A partir de sua análise, torna-se possível diagnosticar que o processo de interiorização apresenta a participação da sociedade civil e do setor empresarial para a tentativa de uma melhor inserção socioeconômica dos migrantes venezuelanos, cuja participação desses setores é fundamental à integração em sua nova vida. Apesar de algumas empresas terem realizados contratos com migrantes, tendo em vista a realização de seminários voltados ao estímulo de tal contratação, percebe-se ainda falta de sensibilização de parte da população e do governo do país com os venezuelanos. O pedido de fechamento da fronteira realizado pela governadora Sueli Campos é um exemplo acerca da falta de solidariedade e mecanismos para garantir sua dignidade humana.

No entanto, ainda não é possível identificar maiores efeitos aos venezuelanos, a população brasileira e com as situações de estada prostrada no país, uma vez que ainda não estão disponíveis dados a longo prazo relativos à inclusão de tais pessoas nas cidades hospedeiras. É necessário, ainda, resolver problemas como direitos humanos e todo o tamanho do processo burocrático imposto, a fim de gerar o maior acesso dos venezuelanos a sua documentação, como como cédula de identidade e CPF e, consequentemente, à política de 
interiorização. O governo brasileiro ainda tenta responder as suas obrigações legais com os direitos dos refugiados, visto que muitos sofrem com hostilidades, falta de documentação, segurança e saúde, principalmente devido ao não reconhecimento do status de refúgio. A burocracia torna-se um fator de dificuldade para que os migrantes reivindiquem seus direitos, mas muitos nem têm o conhecimento de quais são eles em outro país, como no Brasil.

Em contrapartida, apesar do início recente do processo de interiorização dos refugiados venezuelanos no Brasil, já é possível identificar a relevância dessa política pelo Governo que respeita a vontade do indivíduo migrante em participar desse processo, de adesão voluntária e por meio da assinatura do termo de voluntariedade, bem como a criação e a execução da Operação Acolhida, coordenada pelo governo federal, com o apoio operacional e logístico das Forças Armadas e com o apoio técnico do ACNUR e da OIM instaurada pela Força Tarefa Humanitária. Sendo assim, identifica-se um nexo militar-humanitário com atuação logística, operacional e técnica dividida entre eles, mas que deve se atentar a os desafios presentes na relação civil-militar, de modo a otimizar os esforços da política de interiorização.

Enquanto as agências humanitárias garantem o apoio técnico, as Forças Armadas congregam seus esforços para proporcionar um apoio operacional e logístico. O nexo militarhumanitário desconstrói a dicotomia geralmente presente entre os dois conceitos, em que suas agendas têm finalidades iguais, uma vez que carregam um princípio base comum, ou seja, a proteção da vida na política de interiorização. Ambas operam em prol da segurança humana, alinhando a perspectiva militar, de segurança, com a civil, fornecendo necessidades básicas.

Nota-se, ainda, a importância da realização de forma conjunta pelo governo brasileiro com as agências internacionais, tendo em vista que, na tentativa realizada em 2014 com os refugiados haitianos, houve uma falta de comunicação entre os agentes envolvidos. Nesse sentido, observa-se o interesse de melhorar a política de interiorização para que os problemas, no estado de Roraima, o menos populoso do Brasil, sejam diminuídos. A partir de práticas conjuntas, é que se alinham ações com compromisso e determinação para garantir uma vida melhor para cada migrante forçado que se encontre no Brasil, em especial, para os venezuelanos. Todavia, o problema do grande fluxo migratório de venezuelanos no país somente cessará a partir da resolução da situação política e socioeconômica na Venezuela.

\section{Referências bibliográficas}

ACNUR. Acordos de cooperação vão acelerar integração de venezuelanos em Roraima. 2018. Disponível em: <http://www.acnur.org/portugues/ 2018/06/21/acordos-de-cooperacaovao-acelerar-integracao-de-venezuelanos-em-roraima/> . Acessado em: 26 out. 2018. 
- Estudo de Captação de Recursos Privados no âmbito do Programa de

Reassentamento no Brasil. 2018. Disponível em: <https://www.ungm.org/

UNUser/Documents/DownloadPublicDocument?docId=701075 > . Acessado em: 2 out. 2018.

BATISTA JR, João; TEIXEIRA, Duda; NONATO, R.; ASANO, C.; ARRUDA, Simone; SENHORAS, Elói Martins. "Expulsar é a saída errada" (entrevista). Revista Veja, n. 25 97, 29 de agosto, 2018.

BÓGUS, Lucia Maria; JAROCHINSKY, João Carlos; JARONCHINSKY, Stéfanie. Os fluxos migratórios mistos e os entraves à proteção aos refugiados. Revista Brasileira de Estudos de População, Belo Horizonte, v. 34, n. 1, 2017, p. 15-30.

BRDE. BRDE será sede do evento Lei de Migração, em parceria com PNUD, ACNUR e Governo Federal. 2018. Disponível em: <http://www.brde.com.br/noticia/ brde-sera-sededo-evento-lei-de-migracao-em-parceria-com-pnud-acnur-e-governo-federal/> . Acessado em: 26 out. 2018.

CASA CIVIL [BRASIL]. Histórico, 2018. Disponível em: <http://www.casacivil.gov.br/operacao-acolhida/historico>. Acessado em: 04 out. 2018.

_. Interiorização de Imigrantes: resultados e programação para setembro. 2018. CÂMARA DOS DEPUTADOS [BRASIL]. Legislação Informatizada - DECRETO No 9.285. 2018. Disponível em: <http://www2.camara.leg.br/legin/fed/decret/2018/decreto-928515-fevereiro-2018-786170-publicacaooriginal-154864-pe.html>. Acesso em: 26 out. 2018.

CUTTI, D.; MAGALHÃES, D.; PARISE, P.; PATARRA, N. Políticas Públicas e a Migração Internacional no Brasil. Centro de Estudos Migratórios, São Paulo, 2011.

FIESP. Nova Lei de Migração: Uma Janela de Oportunidades. 2018. Disponível em: $<$ http://www.fiesp.com.br/agenda/nova-lei-de-migracao-uma-janela-de-oportunidadescampinassp/>. Acessado em: 26 out. 2018.

FOLHA DE SÃO PAULO. Bilionário para Roraima para acolher venezuelanos. 2019. Disponível em: <https://www1.folha.uol.com.br/mundo/2019/05/bilionario-se-muda-pararoraima-para-acolher-venezuelanos.shtml>. Acessado em: 29 mai. 2019.

FRANCHI, T. Operação Acolhida: A Atuação das Forças Armadas Brasileiras no Suporte aos Deslocados Venezuelanos. Military Review, jan. 2019. Disponível em:

$<$ https://www.armyupress.army.mil/Portals/7/militaryreview/Archives/Portuguese/Online\%20 Exclusives/Franchi-operacao-acholhida-a-atuacao-das-forcas-armadas-brasileiras-no-suporteaos-deslocados-venezuelanos-Jan-2019-1.pdf>. Acessado em: 19 ago. 2019.

FRANKE, V. The Peacebuilding Dilemma: Civil-Military Cooperation in Stability Operations. International Journal of Peace Studies, v. 11, n. 2, 2006. Disponível em: <https://pdfs.semanticscholar.org/4db0/9c3c0bc8174f0734c722023f3d626174fe14.pdf>. Acessado em: 19 ago. 2019.

GARELLI, Glenda; TAZZIOLI, Martina. Containment Beyond Detention: the hotspot system and disrupted migration movements across Europe. Environment and Planning D: Society and Space, fev. 2018a. Disponível em: < 
https://journals.sagepub.com/doi/abs/10.1177/0263775818759335\#articleCitationDownloadC ontainer> Acessado em: 19 jun. 2019.

_. The Humanitarian War Against Migrant Smugglers at Sea. Antipode, v.50, n.3, jun. 2018b, p.685-703. Disponível em: < https://onlinelibrary.wiley.com/doi/pdf/10.1111/anti.12375> Acesso em: 10 jun. 2019.

GOVERNO DO BRASIL [BRASIL]. Especial Venezuelanos, 2018. Brasília: Governo, 2018. Disponível em: <http://www.brasil.gov.br/especial-venezuelanos>. Acessado em: 27 out. 2018.

GONÇALVES, Mirian; NETO, Thiago Maciel; VARELLA, Leonardo. Operações das Forças Armadas Brasileiras na Assistência Humanitária na Região da Amazônia Ocidental. Paper apresentado no XXXIV Encontro Nacional de Engenharia de Produção, Curitiba, PR, 07 a 10 de outubro de 2014. Disponível em: <

http://www.abepro.org.br/biblioteca/enegep2014_TN_STO_195_103_25696.pdf > Acessado em: 19 jul. 2019.

G1 Jornal. Venezuela reabre fronteira com o Brasil, G1 Notícias, 2019. Disponível em: $<$ https://g1.globo.com/mundo/noticia/2019/05/10/venezuela-anuncia-reabertura-da-fronteiracom-o-brasil.ghtml>. Acessado em: 12 ago. 2019.

_. Após juiz mandar fechar fronteira para venezuelanos, AGU pede ao STF urgência na suspensão do decreto do governo de RR. G1 Notícias, 2018. Disponível em:

<https://g1.globo.com/rr/roraima/noticia/2018/08/06/apos-juiz-mandar-fechar-fronteira-paravenezuelanos-agu-pede-ao-stf-urgencia-na-suspensao-do-decreto-do-governo-de-rr.ghtml > Acessado em: 26 out. 2018.

- 'Prefiro morrer de fome na Venezuela do que agredido aqui', diz imigrante atacado por brasileiros na fronteira em RR. G1 Notícias, 2018. Disponível em:

$<$ https://g1.globo.com/rr/roraima/noticia/2018/08/18/prefiro-morrer-de-fome-na-venezuelado-que-agredido-aqui-diz-imigrante-atacado-por-brasileiros-na-fronteira-em-rr.ghtml $>$

Acessado em: 27 out. 2018.

_. Rosa Weber nega fechar fronteira do Brasil com a Venezuela, mas não revoga decisão de juiz que mandou bloquear. G1 Notícias 2018. Disponível em:

$<$ https://g1.globo.com/politica/noticia/2018/08/06/rosa-weber-nega-fechar-fronteira-do-brasilcom-a-venezuela-mas-nao-revoga-decisao-de-juiz-que-mandou-bloquear.ghtml >. Acessado em: 26 out. 2018.

JAROCHINSKI, João Carlos; JUBILUT, Liliana. Venezuelans in Brazil: challenges of protection. E-International Relations, 12 jul. 2018. Disponível em: < https://www.eir.info/2018/07/12/venezuelans-in-brazil-challenges-of-protection/> Acessado em: 15 jul. 2019.

As Fronteiras do Norte do Brasil e o Acesso aos Direitos Sociais. Textos e Debates, v.2, n.27, 2015, p.335-347. Disponível em: < https://revista.ufrr.br/textosedebates/article/view/3212> Acessado em: 20 jul. 2019.

MARQUES, Andressa; LEAL, Marília. Migrantes venezuelanos no Brasil: Cooperação como meio para garantir direitos. Anais do Congresso Nacional de Direitos Difusos, jan. 2018. 
Disponível em: <https://www.editorarealize.com.br/revistas/conidif/trabalhos/

TRABALHO_EV082_MD1_SA7_ID321_21082017230856.pdf\&g>. Acessado: 27 out. 2018.

MIGRAMUNDO. Às vésperas de interiorização, venezuelanos sofrem com hostilidades em RR, 2018a. Disponível em: <http://migramundo.com/as-vesperas-de-interiorizacaovenezuelanos-sofrem-com-hostilidades-em-rr/>. Acessado em: 04 out. 2018.

Nova portaria permite residência temporária de venezuelanos no Brasil, 2018b. Disponível em: <https://migramundo.com/nova-portaria-permite-residencia-temporaria-devenezuelanos-no-brasil/> . Acessado em: 03 jan. 2019.

Sob expectativa, começa interiorização de venezuelanos pelo Brasil, 2018c. Disponível em: <http://migramundo.com/sob-expectativa-comeca-interiorizacao-devenezuelanos-pelo-brasil/>. Acessado em: 04 out. 2018.

MINISTÉRIO DA DEFESA [BRASIL]. Processo de interiorização leva venezuelanos de Roraima para outras regiões do Brasil. Brasília: Ministério da Defesa, 2018. Disponível em: <https://www.defesa.gov.br/noticias/41442-processo-de-interioriza\%C3\%A7\%C3\% A3o-leva-venezuelanos-de-roraima-para-outras-regi\%C3\%B5es-do-brasil>. Acessaddo em: 04 out. 2018.

\section{ORGANIZAÇÃO INTERNACIONAL PARA AS MIGRAÇÕES [OIM]. Regional Action}

Plan: strengthening the regional response to large-scale migration of venezuelans nationals in south america, north america, central america and the Caribbean. Buenos Aires/San José:

IOM Regional Office for South America and Central America, North America and the Caribbean, jan. 2018a. Disponível em: <> Acessado em: 20 out. 2019.

- Brasil - Estratégia de Interiorização dos Venezuelanos. Publicação em conjunto com o Governo do Brasil - Casa Civil. Brasília: Casal Civil, 22 nov. 2018b. Disponível em: < http://www.casacivil.gov.br/operacao-acolhida/documentos/interiorizacao-relatoriocumulativo-22novembro2018.pdf> Acessado em: 20 out. 2019.

Informe Junho 2018. Disponível em: < http://ajufe.org.br/images/2018/09/Informe-OIMBrasil---Junho-2018.pdf> Acessado em: 25 jul. 2019.

Brasil n.2: Monitoramento do Fluxo Migratório Venezuelano - com ênfase em crianças e adolescentes. Brasília: Escritório da OIM no Brasil, 2018d. Disponível em: < https://r4v.info/es/documents/download/66851 > Acessado em: 25 jul. 2019.

ONUBR. Agências da ONU continuam a apoiar o governo brasileiro na interiorização de venezuelanos. 2018. Disponível em: <https://nacoesunidas.org/agencias-da-onu-continuam-aapoiar-o-governo-brasileiro-na-interiorizacao-de-venezuelanos/>. Acessado em: 15 ago. 2018.

_. Sem doações, 1 milhão de refugiados da Somália ficam sem esperança de regressar ao país. 2017. Disponível em: <https://nacoesunidas.org/sem-doacoes-1-milhao-derefugiados-da-somalia-ficam-sem-esperanca-de-regressar-ao-pais/>. Acessado em 16 set. 2018.

PLANALTO [BRASIL]. EMI no 1 /2018 CC-PR/MJSP/MD/GSI-PR. 2018. Disponível em: <http://www.planalto.gov.br/ccivil_03/_Ato2015-2018/2018/Exm/Exm-MP-820-18.pdf>. Acessado em: 26 out. 2018. 
ROBERTS, Nancy. Spanning "Bleeding” Boundaries: Humanitarism, NGOs, and the Civilian-Military Nexus in the Post-Cold War Era. Public Administration Review, v.70, n.2, 2010, p.212-222. Disponível em: <https://core.ac.uk/download/pdf/36733149.pdf>. Acessado em: 19 ago. 2019.

SILVA, Fernanda; VALDES, Lysian. O Processo de Interiorização dos Migrantes Venezuelanos no Brasil. Defesanet, 31 ago. 2018. Disponível em:

$<$ http://www.defesanet.com.br/ven/noticia/30367/O-processo-de-interiorizacao-de-migrantesvenezuelanos-no-Brasil/> Acessado em: 10 set. 2018.

SUPREMO TRIBUNAL FEDERAL [STF]. Governadora de Roraima pede que União feche fronteira do Brasil com a Venezuela. STF Portal, 2018a. Disponível em:

$<$ http://www.stf.jus.br/portal/cms/verNoticiaDetalhe. asp?idConteudo=375419>. Acesso em: 26 out. 2018.

Ação Cível Originária 3121. Brasília: STF, 2018. Disponível em: <http://portal.stf.jus.br/processos/detalhe.asp?incidente=5437155>. Acessado em: 26 out. 2018.

TUZUN, Lilian. An Investigation of the Strategy of Interiorization of the Venezuelans Refugees in Brazil. International Journal of Society Researches, v. 8, n.15, 2018, p. 16981715.

WEISS, Thomas George. Military-Civilian Interactions: humanitarian crises and the responsibility to protect. Londres: Rowman \& Littlefield, 2005. 

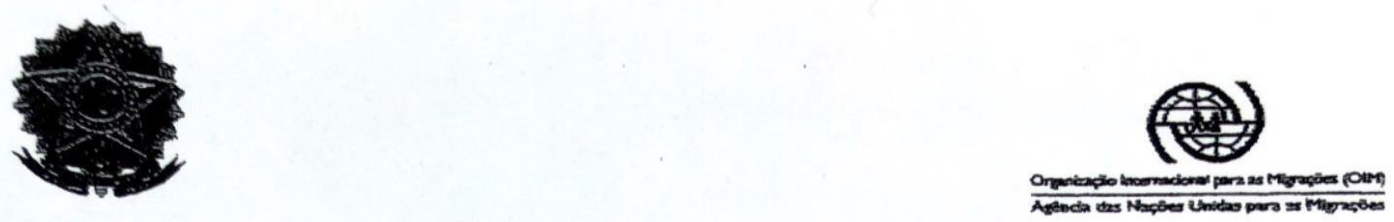

Declaración de Voluntad y Consentimiento Estrategia de Internalización

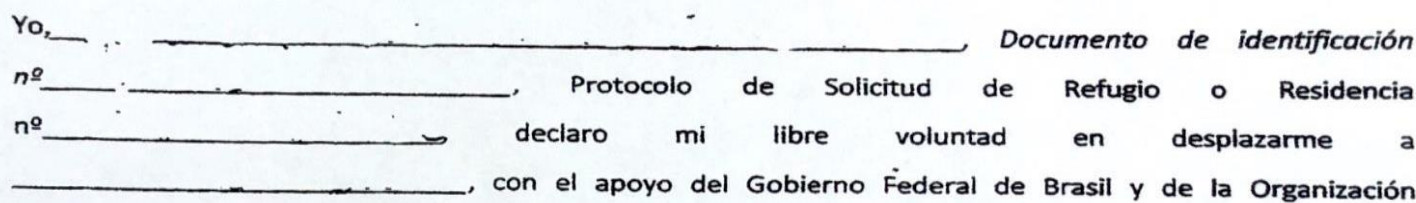

Internacional para las Migraciones (OIM).

Confirmo que he sido informado sobre el apoyo que voy a recibir, así como sobre las condiciones del proceso de internalización, que incluye el transporte a una ciudad brasileña donde voy a ser albergado temporalmente, de acuerdo a las condiciones en documento adjunto.

He sido informado que la estrategia de internalización no implica automaticamente en mi regularización migratoria, y estoy conciente de que caso la decisión sobre mi pedido de regularización migratória esta pendiente, debo acompañar su tramitación junto a la Policia Federal del sítio donde me encuentre ubicado(a).

Confirmo que he sido informado que la estrategia de internalización no implica en oferta de empleo o vivienda fija.

Reconozco, en mi nombre y en nombre de mis dependientes legales abajo, que las instituciones y organizaciones involucradas en el programa no serán responsables por cualquier daño, directo o indirecto, que. sea resultado de eventos que no puedan controlarse por esas instituciones y organizaciones.

Estoy de acuerdo que mis datos personales puedan compartirse solamente con los miembros del Subcomité Federal de la Internalización de los Inmigrantes, establecida por la Resolución n.o 2, de 26 de marzo de 2018, del Comité Federal de Asistencia Emergencial, y con las organizaciones responsables por la recepción en las ciudades de destino, con la finalidad de hacer que funcionen los procesos de presalida, transporte y recepción del programa de intemalización.

Declaro que he suministrado a la OIM o a sus socios toda la información relativa a cualquier condiciones médicas que puedan afectar mi salud y bienestar y los de las demás personas durante el proceso de desplazamiento. Declaro también que, caso alguna de las informaciones suministradas previamente sufrir cualquier cambio hacia el momento del embarque, lo informaré inmediatamente a la oIM.

Declaro que las informaciones que he suministrado son verdaderas y correctas. Comprendo que en caso de falso testimonio al firmar este documento, podrá no ser posible para la OIM dar continuidad al proceso de apoyo.

Estoy de acuerdo con las condiciones indicadas arriba $y$ accepto voluntariamente participar de este proceso de internalización en Brasil, junto a mis dependientes identificados abajo (si procede):

Nombre

Edad

Relación Familiar

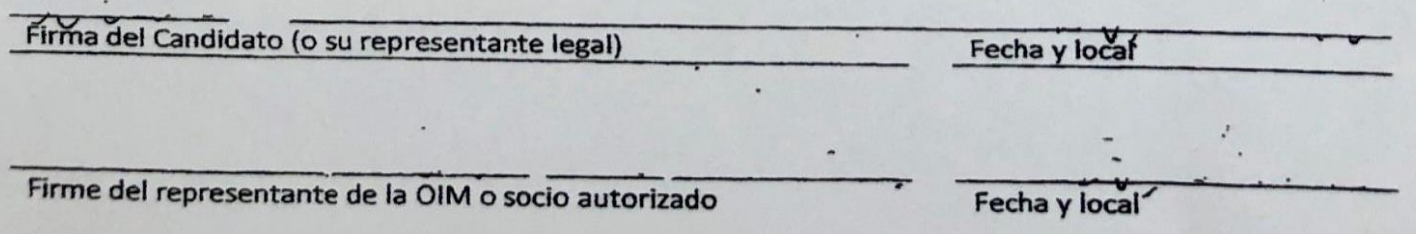

Firma del representante de la Subcomisión Federal de Fecha y local Internalización de los Inmigrantes

Fonte: (cedido pela própria autora deste presente trabalho). 